\title{
Effect of Fluid Flow Direction on Charging of Multitube Thermal Energy Storage for Flat Plate Solar Collectors
}

\author{
Ramalingam Senthil ${ }^{*}$
}

Department of Mechanical Engineering, SRM Institute of Science and Technology, Kattankulathur, Chennai, India

\begin{abstract}
Flat plate solar collector plays a significant role in domestic water heating due to the ease of operation and maintenance. Thermal energy storage with phase change materials is used to store heat energy. The thermal performance of paraffin wax-based multitube latent heat storage with a flat plate solar collector is investigated experimentally. The present work focuses on the fluid flow direction for charging and discharging in a vertical multitube-based thermal storage unit. The charging process took about four hours, with a fluid flow rate of $0.02 \mathrm{~kg} / \mathrm{s}$ at about $70^{\circ} \mathrm{C}$. The flat plate solar collector's thermal efficiency is $56.42 \%$ for the fluid flow rate of 0.02 $\mathrm{kg} / \mathrm{s}$ at the average solar radiation of about $600 \mathrm{~W} / \mathrm{m}^{2}$. During the discharge process, there was an increase in water temperature by $40^{\circ} \mathrm{C}$ at a fluid flow rate of $0.01 \mathrm{~kg} / \mathrm{s}$ in 30 minutes. The 25 -liters of water is circulated to discharge the stored heat. The heat storage effectiveness is varied between about 0.4 and 0.75 . During the discharge, the flow of water from the center to the periphery showed about a 1.7\% higher temperature than that of the water from the periphery to the center. For charging the heat storage, the preferred fluid flow mode is from the periphery to the center. The employment of latent heat storage with a solar collector is beneficial for our thermal needs after sunshine hours.
\end{abstract}

Keywords: Thermal energy storage, solar energy, phase change material, charging process, heat transfer fluid, flat plate solar collector.

Article History: Received: $2^{\text {nd }}$ December 2020; Revised: $0^{\text {th }}$ January 2021; Accepted: $25^{\text {th }}$ January 2021; Available online: $1^{\text {st }}$ February 2021 How to Cite This Article: Senthil, R. (2021) Effect of Fluid Flow Direction on Charging of Multitube Thermal Energy Storage for Flat Plate Solar Collectors. International Journal of Renewable Energy Development, 10(2), 365-371.

https://doi.org/10.14710/ijred.2021.34931

\section{Introduction}

Due to global warming awareness by burning of fuels for our thermal needs, an alternative measure to produce the energy required towards sustainable energy development. Solar energy is renewable and more convenient to produce thermal and electrical power. Solar energy is available annually for about 300 days in India. The utilization of solar rays for various thermal applications carried out for decades of commercial deployments.

Flat plate solar collectors (FPSC) are used for lowtemperature applications. The concentrated solar collectors are useful in attaining higher temperatures for steam production and power generation. Solar energy is a variable source of energy. Hence, an application requires efficient thermal energy storage (TES) to retain heat during peak radiation for later uses. Phase change materials (PCM) contribute to effective thermal management due to high energy density and nearconstant temperature phase change. However, the thermal conductivity of PCM is the main hindrance to large-scale commercial deployment. The operating temperature of suitable PCM for an FPSC is in the range of $50-80^{\circ} \mathrm{C}$. The selective PCMs are fatty acids, paraffin wax, salt hydrates, and eutectics.

The energy-saving capability of the storage tank with PCM improved by $34 \%$. Cost-effective thermal conductivity enhancement of PCM involved the metallic fins and orientation of heat transfer fluid (HTF) and the position of PCM (Elbahjaoui et al. 2019). The PCM with solar collectors observed with excellent usability and heat energy storage density (Senthil, 2019; Rashidi et al. 2020; Senthil et al. 2020). The charging of PCM is an essential aspect of latent heat TES (LHTES). Paraffin wax is generally used in low-temperature applications.

Several researchers investigated various techniques of enhancing heat transfer in PCM (Tony et al. 2020). The frosting issue of the solar water heater (SWH) is investigated to improve solar collectors' thermal performance by modeling the integrated collector storage for SWH (Bilardo et al. 2019). The productivity improvement was observed up to 2.3 times with PCM used with solar collectors (Abu-Arabi et al. 2020). The thermal efficiency of shot peen FPSC was observed at about $54.24 \%$ at a flow rate of $0.02 \mathrm{~kg} / \mathrm{s}$ (Poongavanam et al. 2020). Sensible heat storage was useful to maintain fluid temperatures of about $50^{\circ} \mathrm{C}$ (Alptekin et al. 2020). Further, the HTF flow rate and mass of the PCM are essential parameters. PCM's low conductivity requires more heat input and time due to the fluid's heat content, reducing from inlet to outlet.

Further, various enhancement methods of FPSC have been recently investigated to improve overall system

\footnotetext{
* Corresponding author: senthilr@srmist.edu.in
} 
performance (Majumdar and Saha, 2019). For lowtemperature applications, highly conductive materials like copper and aluminum with nanofluids are useful. However, stainless steel is preferably used due to its anticorrosion nature. For paraffin wax as PCM, the copper is compatible, and stainless is useful if the HTF is water. Multiple PCM to manage the thermocline was studied by several researchers (Shirinbakhsh et al. 2018). Thus, the combinations of enhancement techniques are needed to be explored to enhance the productivity of FPSC using PCM. Several researchers investigated various heat transfer enhancement methods and multiple applications like thermal management of buildings, swimming pools, and solar ponds (Li et al. 2018).

A shell and finned tube latent heat storage was integrated with an SWH and resulted in the highest thermal efficiency of $65 \%$ at the fluid flow rate of $0.16 \mathrm{~kg} / \mathrm{s}$ (Shalaby et al. 2020). The larger surface area between paraffin wax and heat storage minimized the low thermal conductivity of PCM. The charging of PCM was improved in vertical thermal energy storage using a small conical HTF coil at the bottom of the container (Punniakodi and Senthil, 2020). The lower inclination of an SWH of below $20^{\circ}$ was observed to be with a lower electrical consumption compared to a higher collector tilt angle (Santos and Giglio, 2020). Helical fins and conventional finned heat pipes were tested with an evacuated tube solar collector. The maximum temperature difference in the paraffin wax was $4^{\circ} \mathrm{C}$ and $12.25^{\circ} \mathrm{C}$ for the helical and conventional fin systems (Essa et al. 2020).

The various modifications of solar flat plate collectors towards thermal performance were discussed with potential barriers and the respective overcoming methods (Vengadesan and Senthil, 2020). The vertical and horizontal orientation of rectangular PCM containers was investigated under concentrated solar radiation and the vertical position observed with natural convection (Senthil, 2020). The storage tank with multiple outlets proved less impact over the varying solar radiation and operating conditions (Li et al. 2020). Different amounts of PCM and melting temperatures were investigated with solar water heaters in different climatic zones.

The parametric analysis was found to help the design of PCM-based TES (Ding et al. 2020). Two significant decision variables of solar water heating systems were collector area, storage volume, and a thermocline storage tank served better than the conventional hybrid storage tank (Jadhav et al. 2020). With the proper thermocline tank, about $57 \%$ in the collector area and the overall capital investment were reduced. Rajamani et al. (2020) investigated the effect of encapsulated salt PCM composite in the storage tank. The storage tank temperature with PCM was nearly 2.6 to 3.2 more than conventional SWH after the sunset. A thermosiphon SWH was prepared with the locally available materials, and the test results of two climatic conditions proved the comparable performance (Koholé and Tchuen, 2020). The PCM design could be considered to minimize the formation of such thermal barriers (Luu et al. 2020).

From the literature, identifying various methods to store heat and the issues related to storage were recognized. This work aims to enhance the charging of PCM using natural methods instead of using costly additives. The effect of a multitube PCM storage tank for the flow of HTF direction is not investigated much in literature. Latent heat storage is designed with a cylindrical tank embedded with PCM filled copper tubes. This work is investigated to provide the charging and discharging mode for the cylindrical multitube-based LHTES for domestic hot water applications through outdoor experiments using FPSC. Significant results are reported here.

\section{Materials and Methods}

The experimental setup, performance calculations, uncertainty analysis, and experimental procedures are discussed in this section.

\subsection{Experimental work}

A compact PCM storage is investigated for FPSC of commercially available capacity of 100 liters per day. The experimental setup was created using locally, available cost-effective materials. The intended application is domestic hot water; hence, the paraffin wax with a melting point of $60^{\circ} \mathrm{C}$ is selected. Multitube copper tubes of diameter $24 \mathrm{~mm}$ are used as PCM containers. Thus, PCM is encapsulated in cylindrical copper containers. PCM encapsulation is made to capture the heat energy from the low-temperature collector outputs by reducing PCM mass. PCM is kept inside the multitube, and water can flow over the PCM tubes-the increased surface area by encapsulation will completely charge the PCM.

TES works with PCM as charging by hot water from solar collectors and discharging occurs while passing cold water through the PCM storage's copper tube. The charging and discharging (melting and solidification) of PCM are sequential to obtain the maximum utilization. Whenever the demand is there, the HTF is allowed through the storage of an application. During such a process, the partial charging of PCM and hot water supply to the application occurs. Charging of PCM is made by hot water from the solar collector, and discharge emerges from the storage tank where PCM was kept. An effectively insulated tank is conventionally used to store the hot water. PCM's effect is found to be enough to hold in terms of its latent heat with a large quantity of heat at a smaller volume. Figure 1 shows the schematic layout of the FPSC with LHTES.

Table 1 shows the specifications of FPSC and LHTES. A cylindrical stainless container of $150 \mathrm{~mm}$ diameter and $320 \mathrm{~mm}$ height is used as LHTES with PCM filled copper tubes are kept inside the stainless tank. Thermocouples are used in PCM and water inlet and outlet of the LHTES. The total mass of PCM is three kilograms. FPSC and TES were built and tested at outdoor testing. A cylindrical LHTES system is studied to store the heat output of a 100 LPD FPSC. The piping between the FPSC and LHTES is insulated with glass wool of $25 \mathrm{~mm}$ thickness. The hot water from the collector is used to charge the PCM in LHTES. Once the LHTES is fully charged, the stored heat is retrieved with the cold-water supply. The components were assembled, and the setup was tested for the charging and discharging time of the PCM. The energy stored in PCM is mainly latent heat during phase change and sensible heating at single-phase, either solid or liquid PCM. 
Table 1

Specifications of the FPSC and LHTES

\begin{tabular}{|c|c|}
\hline 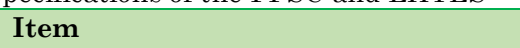 & Values \\
\hline FPSC absorber area & $0.36 \mathrm{~m}^{2}$ \\
\hline Absorber plate material & Copper \\
\hline The thickness of the absorber plate & $0.50 \mathrm{~mm}$ \\
\hline Number of copper tubes & 3 \\
\hline The inner diameter of the HTF tube & $10 \mathrm{~mm}$ \\
\hline Wall thickness of HTF tube & $0.5 \mathrm{~mm}$ \\
\hline Header tube material & Copper \\
\hline The diameter of the header tube & $50 \mathrm{~mm}$ \\
\hline Thermal conductivity of absorber & $386 \mathrm{~W} / \mathrm{mK}$ \\
\hline Number of glass cover & 1 \\
\hline Glass emissivity & 0.88 \\
\hline Space between the glass and absorbers & $30 \mathrm{~mm}$ \\
\hline Insulation material & Glass wool \\
\hline Thermal conductivity of the insulation & $0.04 \mathrm{~W} / \mathrm{mK}$ \\
\hline Tilt angle & $15^{\circ}$ \\
\hline Coating & Black matte paint \\
\hline Size of the LHTES (diameter $\mathrm{x}$ height) & $150 \mathrm{~mm} \times 350 \mathrm{~mm}$ \\
\hline PCM container (diameter $\mathrm{x}$ height) & $24 \mathrm{~mm} \times 330 \mathrm{~mm}$ \\
\hline LHTES container materials & Stainless steel \\
\hline Wall thickness of LHTES & $1.5 \mathrm{~mm}$ \\
\hline Wall thickness of PCM tube & $0.9 \mathrm{~mm}$ \\
\hline Insulation material & Glass wool \\
\hline Thickness of insulation & $32 \mathrm{~mm}$ \\
\hline
\end{tabular}

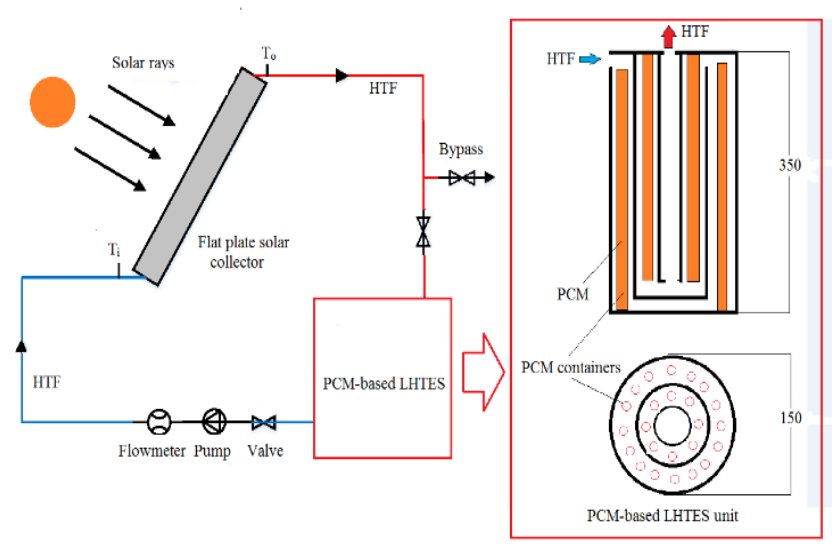

Fig. 1. Schematic layout of LHTES with FPSC (All dimensions are in $\mathrm{mm}$ )

\subsection{Experimental procedure}

The outdoor experiments were conducted on FPSC integrated LHTES at the test site in Chennai, India (Latitude \& Longitude: $12.82^{\circ} \mathrm{N}, 80.04^{\circ} \mathrm{E}$ ) in February 2020. A weather station is used to measure solar radiation, wind speed, and ambient temperature at the site during the test durations. The input and output temperature values were measured at an interval of 10 minutes. Fluid and PCM temperatures were recorded by using a data logging system (34970A, Agilent Technologies). The similar input conditions accounted for studying and comparing the performance of the solar thermal system. During the charging process, the hot water coming out from the FPSC is pumped to the LHTES at a flow rate of $0.02 \mathrm{~kg} / \mathrm{s}$, and effective charging is considered. The outdoor tests started at 8.30 AM of the day, and the readings are plotted for every thirty minutes. During the discharge process, the HTF flow rate of 0.01 $\mathrm{kg} / \mathrm{s}$ was selected to retrieve the PCM heat. The charging and discharging experiments were conducted on five days for each mode of operation. The charging and discharging of FPSC on a sunny day are considered in the results section to compare the discharge modes of passing heat transfer fluid centre to periphery and vice versa.

\subsection{Thermal Performance calculations}

The thermal performance of FPSC with LHTES is determined based on energy efficiency and storage effectiveness, respectively. The useful heat gained by the FPSC is given by Eq. (1),

$$
Q_{u}=\dot{m} C_{P}\left(T_{o}-T_{i}\right)
$$

The collector thermal efficiency is given by Eq. (2)

$\eta_{e n}=\frac{\dot{m} C_{P}\left(T_{o}-T_{i}\right)}{I_{g} A_{c}}$ 
Where, $\dot{m}$ is HTF flow rate $(\mathrm{kg} / \mathrm{s}), C_{p}$ is the specific heat of HTF $(\mathrm{kJ} / \mathrm{kg}-\mathrm{K}), I_{g}$ is the solar radiation $\left(\mathrm{W} / \mathrm{m}^{2}\right), A_{c}$ is the solar collector surface area $\left(\mathrm{m}^{2}\right), T_{i}, T_{o}$ are HTF inlet and outlet temperature (K).

Table 2 shows the PCM properties. The total heat stored in PCM is given by Eq. (3),

$Q=\int_{T_{i}}^{T_{m}} m \cdot C_{p c m(\text { solid })} \cdot d T+m \cdot H+\int_{T_{m}}^{T_{f}} m \cdot C_{p c m(\text { liquid })} \cdot d T$

Where, Ti, Tf, and Tm are the initial, final, and melting temperatures of PCM $(\mathrm{K}), \mathrm{m}$ is the mass of PCM $(\mathrm{kg}), H$ is the latent heat of PCM $(\mathrm{kJ} / \mathrm{kg}), \mathrm{C}_{\mathrm{pcm}}$ is the specific heat of PCM (kJ/kg-K).

The storage effectiveness is determined as per Eq. (4),

$\varepsilon=\frac{\left(T_{o}-T_{i}\right)}{\left(T_{o}-T_{p c m}\right)}$

Where, $T_{p c m}$ - Average temperature of PCM (K).

\subsection{Uncertainty analysis}

RTD sensors are used to measure the HTF and PCM temperatures. An uncertainty analysis is carried out (Kline and McClintock, 1953; Moffat, 1988). The uncertainty values of thermal efficiency of FPSC and storage effectiveness of LHTES are determined based on the uncertainty values of measurement of the HTF flow rate, solar radiation, and HTF temperatures using Eq. (5) and (6), respectively. The overall uncertainty of thermal efficiency and storage effectiveness of the selected FPSC is determined by about $\pm 3.3 \%$ and $1.9 \%$, respectively. Thus, the instruments are at the desired accuracy level during the experimentation. The uncertainty of the experiment is shown in Table 3.

$$
\begin{aligned}
& \delta \eta_{e n}= \\
& \sqrt{\left(\frac{\delta \eta}{\delta \dot{m}}\right)^{2}(\delta \dot{m})^{2}+\left(\frac{\delta \eta}{\delta I}\right)^{2}(\delta I)^{2}+\left(\frac{\delta \eta}{\delta T_{i}}\right)^{2}\left(\delta T_{i}\right)^{2}+\left(\frac{\delta \eta}{\delta T_{o}}\right)^{2}\left(\delta T_{o}\right)^{2}} \\
& \delta \varepsilon=\sqrt{\left(\frac{\delta \varepsilon}{\delta T_{p c m}}\right)^{2}\left(\delta T_{p c m}\right)^{2}+\left(\frac{\delta \varepsilon}{\delta T_{i}}\right)^{2}\left(\delta T_{i}\right)^{2}+\left(\frac{\delta \varepsilon}{\delta T_{o}}\right)^{2}\left(\delta T_{o}\right)^{2}}
\end{aligned}
$$

Table 2

Properties of paraffin wax (RT60)

\begin{tabular}{lc}
\hline Property & Values \\
\hline Melting point & $60^{\circ} \mathrm{C}$ \\
Latent heat & $184 \mathrm{~J} / \mathrm{g}$ \\
Thermal conductivity & $0.18 \mathrm{~W} / \mathrm{mK}$ \\
Thermal expansion & $11 \%$ \\
Density & $786 \mathrm{~kg} / \mathrm{m}^{3}$ (liquid), $834 \mathrm{~kg} / \mathrm{m}^{3}$ (solid) \\
Specific heat & $2.44 \mathrm{~J} / \mathrm{gK}$ (liquid), $2.4 \mathrm{~J} / \mathrm{gK}$ (solid) \\
\hline
\end{tabular}

Table 3

Uncertainties in the measurement of parameters

\begin{tabular}{cc}
\hline Property & Uncertainty \\
\hline Solar radiation & $\pm 20 \mathrm{~W} / \mathrm{m}^{2}$ \\
Mass flow rate & $\pm 0.01 \mathrm{~kg} / \mathrm{h}$ \\
Temperature & $\pm 0.1^{\circ} \mathrm{C}$ \\
Wind speed & $\pm 0.1 \mathrm{~m} / \mathrm{s}$ \\
\hline
\end{tabular}

\section{Results and discussion}

In this section, PCM charging, collector efficiency, the heat stored, and discharging of PCM are discussed.

\subsection{Charging of PCM}

Hot water passed into the LHTES unit at $70^{\circ} \mathrm{C}$ from $\mathrm{SWH}$. The PCM starts charging as heat transfer takes place from water. Total water heated is 25 liters. There is a gradual rise in the temperature of HTF and PCM over the day. The average solar radiation observed about $600 \mathrm{~W} / \mathrm{m}^{2}$. Figure 2 shows the variation of HTF temperature during the charging of PCM under solar radiation. The HTF coming out of the solar collector is passed through the PCM storage to charge the PCM. The temperature of HTF leaving the solar collector increases till noon and decreases later due to the varying solar radiation. Initially, the PCM temperature increases to its melting point, and then the PCM temperature remains the same till the entire PCM becoming liquid. The phase change occurs at almost isothermally. PCM temperature increases after the PCM completely melt. Thus, the sensible and latent heating of PCM occurs. Figure 3 shows the variation of the ambient temperature and wind speed over the site's test duration. The ambient temperature and wind speed varied from about 34 to $37^{\circ} \mathrm{C}$ and $0.5 \mathrm{~m} / \mathrm{s}$ and $2 \mathrm{~m} / \mathrm{s}$, respectively. After about four hours, the temperature of PCM at several measurement locations reaches a melting point, and this condition is considered the attainment of complete charging of PCM.

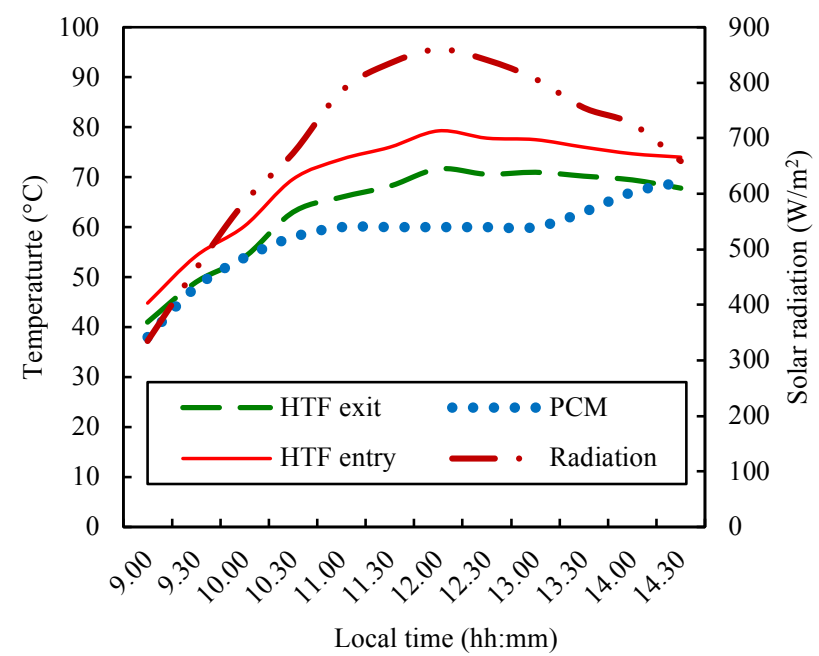

Fig. 2. HTF temperatures and PCM temperature of LHTES over solar radiation on $25^{\text {th }}$ February 2020 


\subsection{Thermal efficiency of FPSC}

The thermal efficiency is plotted against the temperature difference ratio to solar radiation term as shown in Fig. 4. The optical efficiency is determined graphically, about 0.70 . Figure 5 depicts the thermal efficiency variation over the test duration. The peak thermal efficiency of FPSC is $56.42 \%$, and the average efficiency of about $50 \%$. The efficiency varied between $45 \%$ and $60 \%$ for the HTF flow rate of $0.02 \mathrm{~kg} / \mathrm{s}$ at the solar radiation variation of $350-850$ $\mathrm{W} / \mathrm{m}^{2}$.

\subsection{Amount of heat stored in PCM}

The maximum energy stored in the designed LHTES is $990 \mathrm{~kJ}$ as per the PCM's attained operating temperatures. The amount of heat stored in PCM over the measured solar radiation at the site is illustrated in Fig. 6. Charging efficiency is about $70 \%$, and the discharge efficiency is about $80 \%$ due to the longer and shorter operational duration, respectively. The flow rate of HTF is higher during the active heating of LHTES, and a lower HTF flow rate is considered to release the heat stored in PCM. Figure 7 shows the charging trend of PCM and the variation of storage effectiveness over the test duration. The heat storage effectiveness varied between about 0.4 and 0.75 .

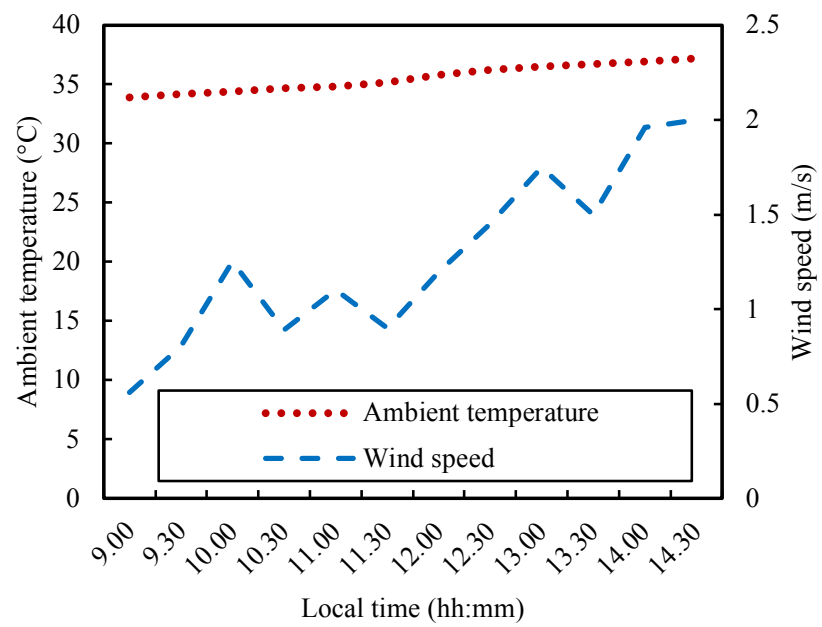

Fig. 3. Variation of ambient temperature and wind speed during the outdoor testing on $25^{\text {th }}$ February 2020

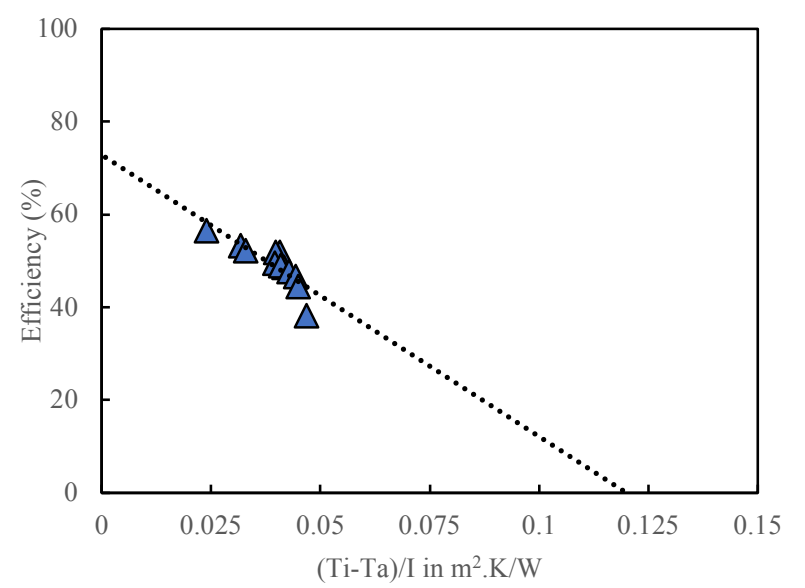

Fig. 4. The efficiency of FPSC at the HTF flow rate of $0.02 \mathrm{~kg} / \mathrm{s}$

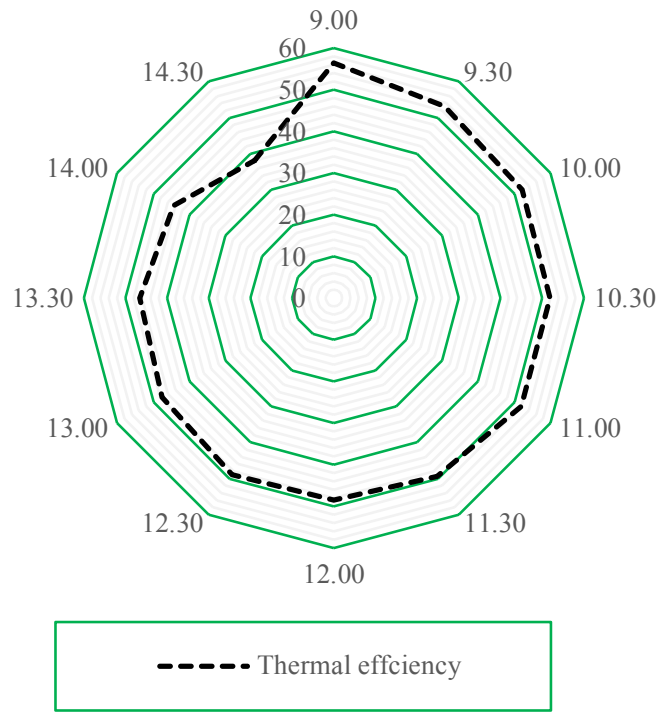

Fig. 5. Variation of the thermal efficiency of FPSC over the time of the day.

\subsection{Discharging of PCM}

The discharge process was carried out with an HTF flow rate of about $0.01 \mathrm{~kg} / \mathrm{s}$. The average temperature of PCM is allowed to reach about $66^{\circ} \mathrm{C}$, which is well above PCM's melting point. There are two modes of operation tested with the same HTF flow rate and PCM temperature on three days. Temperature measurements measure the average temperature of PCM.

For the comparison, trials of one day for each flow mode are compared and illustrated in Fig. 8. HTF temperature increase of about $40^{\circ} \mathrm{C}$ has been observed in thirty minutes during the discharge process while the water's initial temperature was about $30^{\circ} \mathrm{C}$. The PCM starts discharging the heat to water. Passing water from the center to the periphery showed about $1.7 \%$ higher temperature than the mode of supplying water from periphery to center. Hence, the flow of water from the center to the periphery improves heat retrieval due to significant heat absorption. The charging and discharging processes are followed by two modes of operation for effective operations. During PCM charging, the hot water is allowed through the periphery to the center to melt the PCM effectively. Further, to discharge the PCM's heat, cold fluid is passed through the center to the periphery and observed to be effective.

The variation of PCM temperature during the HTF entry from periphery and center and periphery has been observed minimal, approximately $1 \%$ during the discharge processes. During charging, HTF entering peripherally to the LHTES is significant due to the uniform heat flux in PCM. Charging and discharging PCM is the opposite, and similarly, the flow direction of HTF direction is also essential. The performance of the FPSC enhanced its productivity for specific domestic applications. A combination of LHTES and FPSC worked well during the integration, and the PCM employed in a multitube system was observed with effective charging of PCM. 


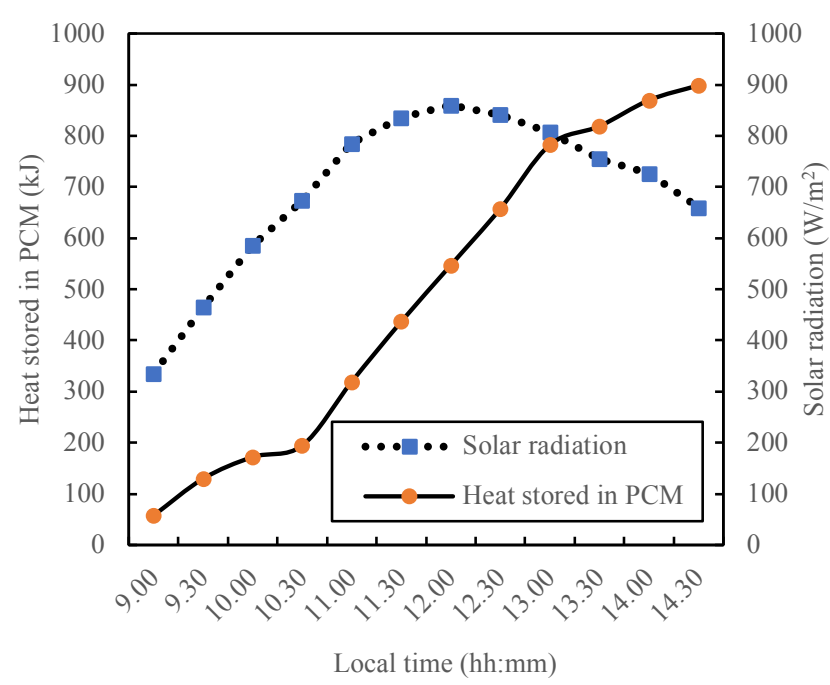

Fig. 6. Quantity of heat stored in PCM over the test duration

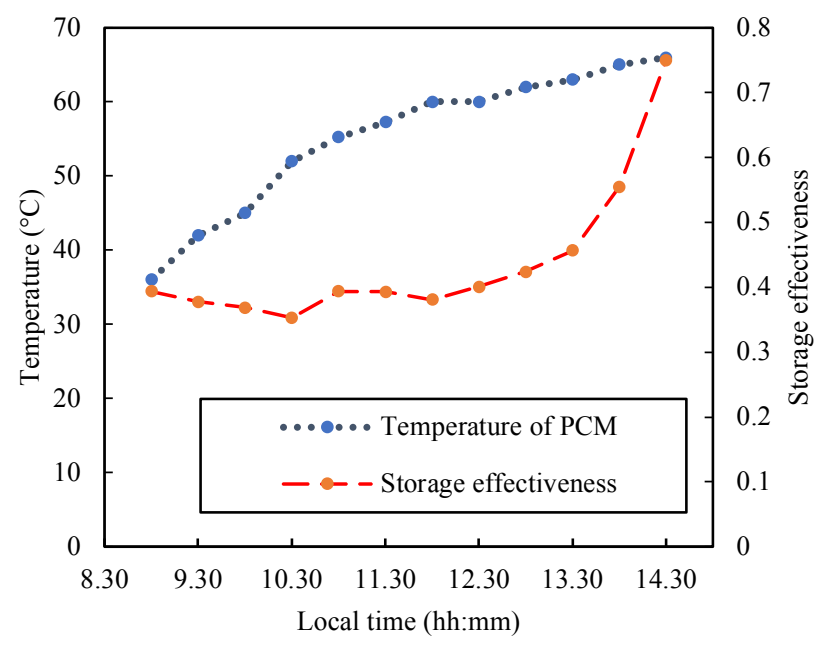

Fig. 7. The heat storage effectiveness of LHTES during the charging of PCM.

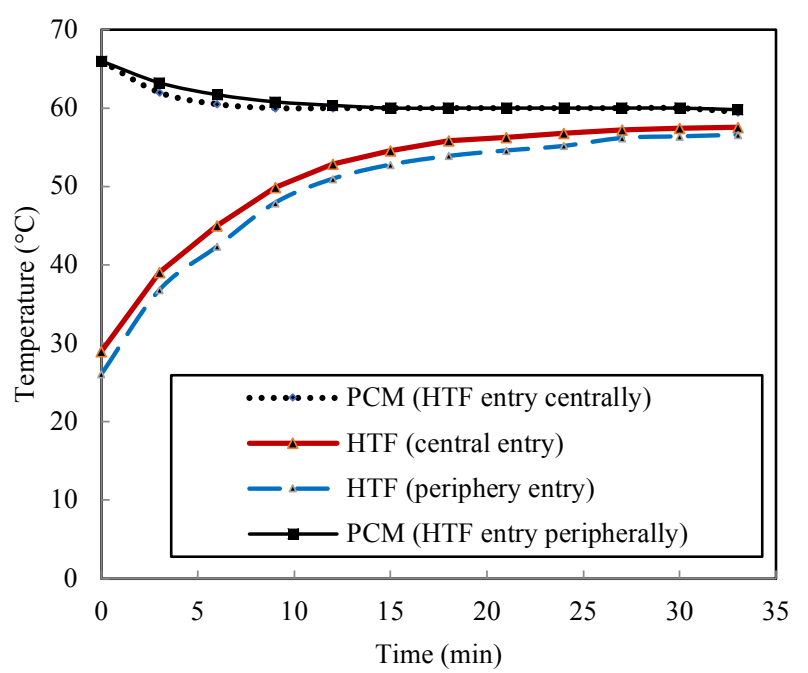

Fig. 8. Variation of HTF temperature during discharging of PCM in two modes of supplying from center to periphery and vice versa.
Table 4

Comparison of the results with the literature

\begin{tabular}{ll}
\hline Type of FPSC & Thermal efficiency (\%) \\
\hline $\begin{array}{l}\text { Sot peen FPSC } \\
\text { (Poongavanam } \text { et al. 2020) }\end{array}$ & $\begin{array}{l}54.24 \% \text { at a flow rate of } \\
0.02 \mathrm{~kg} / \mathrm{s}\end{array}$ \\
$\begin{array}{l}\text { FPSC with integrated } \\
\text { storage (Shalaby } \text { et al. } 2020)\end{array}$ & $\begin{array}{l}65 \% \text { at the fluid flow rate } \\
\text { of } 0.16 \mathrm{~kg} / \mathrm{s}\end{array}$ \\
$\begin{array}{l}\text { FPSC with evacuated tubes } \\
\text { (Wannagosit } \text { et al. } 2020)\end{array}$ & $58.28 \%$ \\
$\begin{array}{l}\text { The present study on FPSC } \\
\text { with multitube TES }\end{array}$ & $\begin{array}{l}56.42 \% \text { for the HTF flow } \\
\text { rate of } 0.02 \mathrm{~kg} / \mathrm{s} \text { at the } \\
\text { average solar radiation of } \\
\text { about } 600 \mathrm{~W} / \mathrm{m}^{2}\end{array}$ \\
\hline
\end{tabular}

The discharge process occurred at a faster rate. FPSC and TES's combined effect is experimentally studied, and the PCM used in energy storage can store the heat energy for the non-solar periods. The comparison of the present results with literature is indicated in Table 4. HTF flow rate and temperature are critical operating parameters during the charging/discharging of PCM.

\section{Conclusions}

An LHTES with multitube has been designed and tested outdoor with an FPSC successfully with enhanced heat transfer. The developed multitube latent heat TES unit has been demonstrated for the selected SWH heater successfully. The major conclusions are given below.

The effective charging process took about four hours for the $\mathrm{HTF}$ temperature of about $70^{\circ} \mathrm{C}$ at a flow rate of 0.02 $\mathrm{kg} / \mathrm{s}$. The heat storage effectiveness of designed LHTES varied between about 0.4 and 0.75 . The complete discharging process of PCM took about 30 minutes, with a water temperature rise of $40^{\circ} \mathrm{C}$ of 25 liters, closer to PCM's melting temperature.

During the discharging, the flow direction of water from the center to the periphery of LHTES showed about 1.7\% higher temperature than the mode of supplying water from periphery to center. The charging of the selected configuration is useful when the HTF is passed from periphery to center. For the discharging, passing HTF from center to periphery is found to be effective.

The natural method of storing energy by enough melting is studied without any thermal performance enhancement methods and techniques using multi tubes made up of copper in a cylindrical container successfully. The LHTES can store the heat in PCM during the heat source availability and is used for thermal building applications. Such a design of LHTES is most beneficial to hold the heat of solar thermal collectors and heat recovery systems in the various processes of industrial and building heating.

\section{References}

Abu-Arabi, M., Al-harahsheh, M., Ahmad, M. \& Mousa, H. (2020). Theoretical modeling of a glass-cooled solar still incorporating PCM and coupled to flat plate solar collector. $J$ Energy Storage, 29, 101372.

Alptekin, E. \& Ezan, M. A. (2020). Performance investigations on a sensible heat thermal energy storage tank with a solar 
collector under variable climatic conditions. Appl Therm Eng $164,114423$.

Bilardo, M., Fraisse, G., Pailha, M. \& Fabrizio, E. (2019). Modelling and performance analysis of a new concept of integral collector storage (ICS) with phase change material. Sol Energy, 183, 425-440.

Ding, Z., Wu, W., Chen, Y. \& Li, Y. (2020). Dynamic simulation and parametric study of solar water heating system with phase change materials in different climate zones. Sol Energy 205, 399-408. https://doi.org/10.1016/j.solener.2020.05.075.

Elbahjaoui, R. \& El Qarnia, H. (2019). Thermal performance of a solar latent heat storage unit using rectangular slabs of phase change material for domestic water heating purposes. Energy Build,. 182, 111-130.

Essa, M. A., Rofaiel, I. Y. \& Ahmed, M. A. (2020). Experimental and Theoretical Analysis for the Performance of Evacuated Tube Collector Integrated with Helical Finned Heat Pipes using PCM Energy Storage. Energy 206, 118166. https://doi.org/10.1016/j.energy.2020.118166.

Jadhav, I. B., Bose, M., Bandyopadhyay, S. (2020). Optimization of solar thermal systems with a thermocline storage tank. Clean Technologies and Environmental Policy 22(5), 10691084. https://doi.org/10.1007/s10098-020-01849-4.

Kline, S. \& McClintock, F. (1953). Describing Uncertainties in Single-Sample Experiments. Mechanical Engineering, 75, 38.

Koholé, Y. W. \& Tchuen, G. (2020). Experimental and numerical investigation of a thermosyphon solar water heater. International Journal of Ambient Energy 41(4),384-394. https://doi.org/10.1080/01430750.2018.1472641.

Li, J., Li, X., Wang, Y. \& Tu, J. (2020). A theoretical analysis of the daily performance of a new water tank with multiple outlets in solar water heating system. J Clean Prod 262, 121166. https://doi.org/10.1016/j.jclepro.2020.121166.

Luu, M. T., Milani, D., Nomvar, M. \& Abbas, A. (2020). A design protocol for enhanced discharge exergy in phase change material heat battery. Appl Energy, 265, 114801.

Majumdar, R. \& Saha, S. K. (2019). Effect of varying extent of PCM capsule filling on thermal stratification performance of a storage tank. Energy, 178, 1-20.

Moffat, R. J. (1988). Describing the Uncertainties in Experimental Results. Experimental Thermal and Fluid Science 1, 3-17.

Poongavanam, G. K., Sakthivadivel, D., Meikandan, M., Balaji, K. \& Vigneswaran, V. S. (2020). Thermal performance augmentation of a solar flat plate collector using the shot peening technique. Sci Technol Built Environ 26(3), 437-445. https://doi.org/10.1080/23744731.2019.1633889.

Punniakodi, B. M. S. \& Senthil, R. (2020). Effect of conical coiled heat transfer fluid tube on charging of phase-change material in a vertical shell and coil type cylindrical thermal energy storage. Energy sources, Part A: Recovery, Utilization, and
Environmental

Effects. https://doi.org/10.1080/15567036.2020.1819476.

Rajamani, P., Balasubramaniam, M. \& Radhakrishnan, K. (2020). Calorimetric investigation of magnesium nitrate hexahydrate and sodium thiosulphate pentahydrate as salt mixture encapsulated materials for thermal energy storage. Thermal Science, 24, 613-621.

Rashidi, S., Yang, L., Khoosh-Ahang, A, Jing, D. \& Mahian, O. (2020). Entropy generation analysis of different solar thermal systems. Environ Sci Pollut Res, 27(17), 20699-20724. https://doi.org/10.1080/23744731.2019.1633889.

Santos, V., Giglio, T. (2020). An approach to investigate the interface between built environment and thermosyphon solar water heating system. Energy and Buildings, 223, 110092. https://doi.org/10.1016/j.enbuild.2020.110092.

Senthil, R. (2019). Effect of Uniform and Variable Fin Height on Charging and Discharging of Phase Change Material in a Horizontal Cylindrical Thermal Storage. Thermal Science 23(3PartB), 1981-1988.

Senthil, R. (2020). Effect of charging of phase change material in vertical and horizontal rectangular enclosures in a concentrated solar receiver. Case Studies in Thermal Engineering, $21, \quad 100653$. https://doi.org/10.1016/j.csite.2020.100653.

Senthil, R., Patel, A., Rao, R. \& Ganeriwal, S. (2020). Melting Behavior of Phase Change Material in a Solar Vertical Thermal Energy Storage with Variable Length Fins added on the Heat Transfer Tube Surfaces. International Journal of Renewable Energy Development, 9(3), 361-367. https://doi.org/10.14710/ijred.2020.29879.

Shalaby, S.M., Kabeel, A. E., Moharram, B. M. \& Fleafl, A. H. (2020). Experimental study of the solar water heater integrated with shell and finned tube latent heat storage $\begin{array}{lllll}\text { system. J Energy Storage, 31, } 101628 . & .\end{array}$ https://doi.org/10.1016/j.est.2020.101628.

Shirinbakhsh, M., Mirkhani, N. \& Sajadi, B. (2018). A comprehensive study on the effect of hot water demand and PCM integration on the performance of SDHW system. Sol Energy, 159, 405-414.

Tony, M. A. \& Mansour, S. A. (2020). Sunlight-driven organic phase change material-embedded nanofiller for latent heat solar energy storage. Int J Environ Sci Technol, 17(2), 709720. https://doi.org/10.1007/s13762-019-02507-z.

Vengadesan, E. \& Senthil, R. (2020). A review on recent development of thermal performance enhancement methods of flat plate solar water heater. Sol Energy, 206, 935-961. http://dx.doi.org/10.1016/j.solener.2020.06.059.

Wannagosit, C., Sakulchangsatjatai, P., Kammuang-Lue, N. \& Terdtoon, P. (2018). Validated mathematical models of a solar water heater system with thermosyphon evacuated tube collectors. Case Studies in Thermal Engineering, 12, 528-536. https://doi.org/10.1016/j.csite.2018.07.005. 